\title{
Pituitary Tuberculoma: An Uncommon Pathology
}

\author{
Praveen Kumar Gupta ${ }^{1}$ Sharad Pandey ${ }^{2}$ Deepa Pandey ${ }^{3}$ \\ ${ }^{1}$ Department of NeuroSurgery, Sir Sunder Lal Hospital, IMS, BHU, \\ Varanasi, Uttar Pradesh, India \\ ${ }^{2}$ Department of NeuroSurgery, P.G.I.M.E.R., Dr Ram Manohar Lohia \\ Hospital, New Delhi, India \\ ${ }^{3}$ Department of Pathology and Microbiology, Northern Railway \\ Central Hospital, New Delhi, India \\ Indian J Neurosurg 2021;1:77-79.
}

\author{
Address for correspondence Deepa Pandey, MD, Department \\ of Pathology and Microbiology, Northern Railway Central \\ Hospital, Connaught Place, New Delhi 110001, India \\ (e-mail: deepalohani02lhmc@gmail.com).
}

\section{Introduction}

Central nervous system tuberculomas account for 0.15 to $4 \%$ of space occupying lesions. However, pituitary tuberculomas are extremely rare. Only handful of cases have been reported in the literature and the first case of intrasellar tuberculoma was reported by Coleman and Meredith. ${ }^{1,2}$ In developing countries where tuberculosis is endemic, intracranial tuberculomas are reported often..$^{1-10}$ Intracranial tuberculomas are usually located in the cerebellum and cerebral cortex and present as tuberculous meningitis, tuberculous encephalitis, tuberculoma, or tuberculous brain abscess, depending on the location of tubercular foci and host immune factors. Gradual onset of headache and visual disturbances with or without systemic symptoms are the common presenting symptoms. This was a rare case of pituitary tuberculoma mimicking a pituitary adenoma which presented with holocranial headache associated with vomiting and significant weight loss.

\section{Case Report}

A 29-year-old male patient presented in our Neurosurgery OPD with bifrontal headache, which spread gradually holocranially within 2 months. Headache was dull aching type, mild to

DOI https://doi.org/

$10.1055 / \mathrm{s}-0039-3401334$

ISSN 2277-954X. moderate in intensity, and associated with on and off episodes of vomiting and used to get relieved after vomiting and oral analgesics. There was history of significant weight loss, 5 to $6 \mathrm{~kg}$ in last 3 months. There was no history of fever, cough, and chest pain, reduction of vision, diplopia, photophobia, visual field defects, coarsening of facial features, increase in hand and feet size, heat and cold intolerance, loss of libido, or decrease hair growth. On examination, patient was conscious, well-oriented, afebrile, blood pressure $126 / 84 \mathrm{~mm} \mathrm{Hg}$, pulse rate (PR) 88 per minute. On eye examination, visual acuity was $6 / 6$ in both eyes and there was no visual field defect. The biochemical and hematological profiles were within normal limits. Erythrocyte sedimentation rate was $15 \mathrm{~mm} / \mathrm{h}$ and X-ray chest was normal. Mantoux test was positive (32-mm induration). Hormone profile was suggestive of deranged thyroid function test as tri-iodothyronine (FT3) $3.08 \mathrm{pg} / \mathrm{mL}$ (2.77-5.27), thyroxine (FT4) $0.75 \mathrm{ng} / \mathrm{dL}(0.78-2.19)$, and thyroid stimulating hormone (TSH) $<0.015 \mu \mathrm{IU} / \mathrm{mL}(0.47-4.68)$. Cortisol level was reduced to $13.06 \mathrm{ng} / \mathrm{mL}$, prolactin was raised to $29.76 \mathrm{ng} / \mathrm{mL}$, follicle-stimulating hormone level was $1.22 \mathrm{mUI} / \mathrm{mL}$, luteinizing hormone (LH) level was $0.98 \mathrm{mUI} / \mathrm{mL}$. On magnetic resonance imaging (MRI), lobulated sellar lesion with suprasellar extension, which was isointense on $\mathrm{T} 1$ and $\mathrm{T} 2$, was reported. Contrast MRI scan showed intense homogenous contrast

(c)2020. Neurological Surgeons' Society of India.

This is an open access article published by Thieme under the terms of the Creative Commons Attribution-NonDerivative-NonCommercial-License, permitting copying and reproduction so long as the original work is given appropriate credit. Contents may not be used for commercial purposes, or adapted, remixed, transformed or built upon. (https://creativecommons.org/licenses/by-nc-nd/4.0/).

Thieme Medical and Scientific Publishers Pvt. Ltd. A-12, 2nd Floor, Sector 2, Noida-201301 UP, India 
enhancement, nonvisualization of pituitary gland with mildly bulky pituitary stalk, which was suggestive of pituitary macroadenoma (- Fig. 1). Surgical intervention was planned and transnasal transsphenoidal excision of the lesion (microscopic + endoscopic) was done. Intraoperatively, the lesion was grayish-white in color, firm in consistency with some caseous material, and CSF leak was present. Postoperatively, continuous lumbar drainage and strict lying down position were advised. Routine microscopic examination of CSF was normal with glucose $63 \mathrm{mg} / \mathrm{dL}$, protein $34 \mathrm{mg} / \mathrm{dL}$, and white blood cell count was 4 per cubic millimeter of CSF. Cerebrospinal fluid-polymerase chain reaction for Mycobacterium tuberculosis was negative. Angiotensin converting enzyme level was $30 \mu \mathrm{L}(9-67 \mu \mathrm{L})$. Histopathological examination revealed dense chronic inflammation and many epitheloid cell granulomas with small focal areas of necrosis which were suggestive of granulomatous inflammation with possibility of tuberculosis ( - Fig. 2). No tumor and no fungal elements were seen. Patient was put on standard antituberculosis treatment and discharged in a stable condition. On follow-up, the patient showed significant improvement symptomatically.

\section{Discussion}

Though pituitary adenomas are the commonest in the sellar region, but unusual nonadenohypophyseal lesions and inflammatory pathologies must be considered in the differential diagnosis of a sellar mass. Pituitary tuberculomas have been usually reported to occur predominantly in adult women aged between 40 and 60 years. ${ }^{4-6,10,11}$ Most of these cases have been reported in previously healthy people with no evidence of immunosuppression. Only 25 to $30 \%$ of the cases with sellar tuberculomas have past or concurrent history of extrasellar tuberculosis. ${ }^{4}$
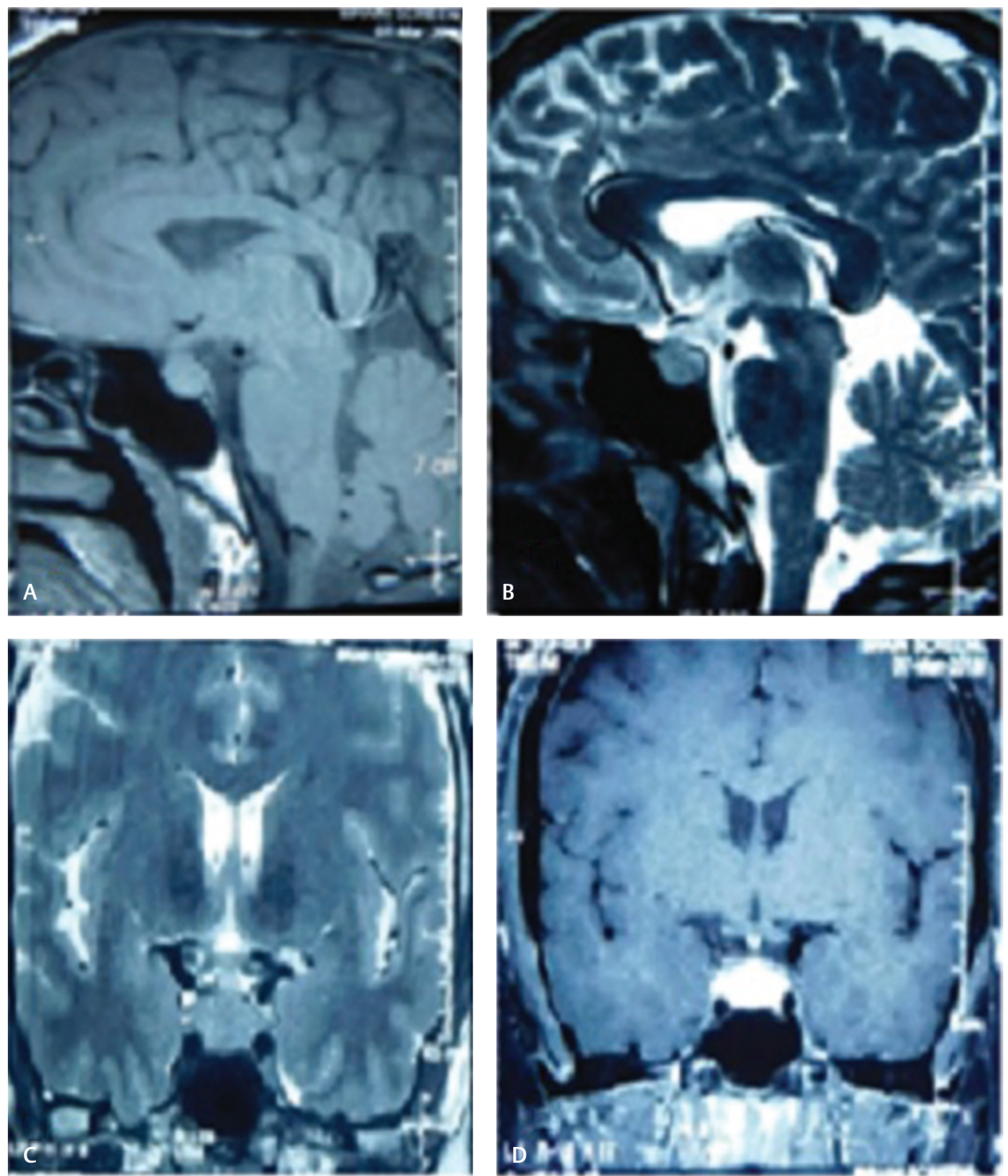

Fig. 1 Preoperative MRI findings (A) plain MRI sagittal view showing isointense lesion on $\mathrm{T}_{1}$-weighted image, (B, C) plain MRI sagittal and coronal view showing isointense lesion on $\mathrm{T}_{2}$-weighted MRI, (C) contrast MRI coronal view showing homogenous enhancement. MRI, magnetic resonance imaging. 


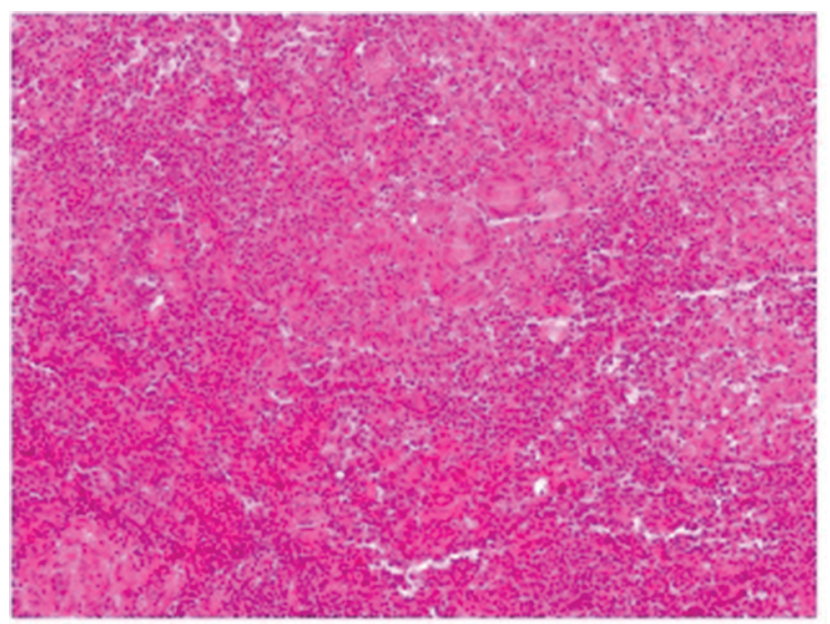

Fig. 2 Histopathological examination revealed dense chronic inflammation and many epithelioid cell granulomas with small focal areas of necrosis.

In this case, patient presented with headache and occasional vomiting with significant weight loss without any visual symptoms. Significant weight loss and positive Mantoux test were important findings. Also, endocrinological evaluation revealed deranged thyroid function tests with lower cortisol level and raised prolactin level. Pituitary and suprasellar lesions can interfere with normal delivery of prolactin-inhibitor factor to the adenohypophysis resulting into hyperprolactinemia. Isolated pituitary tuberculomas usually mimic pituitary adenomas ${ }^{4-6,10,11}$ and it was impossible to diagnose without surgical specimens. In most of the cases, pituitary tuberculomas have good outcomes if treated with antituberculous therapy adequately. ${ }^{1,4-7,10,11}$ Thus, the main purpose of surgery is to obtain a specimen for histological diagnosis to exclude other pathological causes (like infection, common sellar lesions such as pituitary adenomas and Rathke's cleft cysts), and surgical decompression.

Thus, the postoperative pathological diagnosis indicating the tuberculous lesion prompted us to do a retrospective assessment of MRI finding which was pituitary macroadenoma as a lobulated sellar lesion with suprasellar extension showing homogenous contrast enhancement, with pituitary stalk in midline and mildly bulky with $4.5 \mathrm{~mm}$ in thickness. Also, it is important to mention that hypophyseal tuberculomas may be often mistaken for pituitary adenomas. The finding of a "thickened pituitary stalk" in contrast magnetic resonance imaging scans may be useful in differentiation of such lesions from pituitary adenomas. In many reports, sellar tuberculomas were finally diagnosed by only indirect pathological findings such as necrotizing granulomas. ${ }^{1,4,6,10,11}$ A histologically important feature of granulomas is whether or not they contain necrosis. ${ }^{1}$ The presence of necrosis in granulomas is important because granulomas with necrosis tend to have infectious causes, typically tuberculosis. The differential diagnosis of pituitary granulomatous diseases includes sarcoidosis, syphilis, paranasal fungal infections, lymphocytic and granulomatous hypophysitis, and Wegener's granulomatosis. ${ }^{1,4,6,7,10,11}$ In this case, strongly positive Mantoux test and histopathological diagnosis of epithelioid cell granulomas with necrosis strongly indicated the granulomatous pituitary lesion was due to tubercular pathology. The transsphenoidal approach is the recommended surgical approach, because it permits both tissue diagnosis and tumor decompression without cerebrospinal fluid contamination. ${ }^{1,4-7,11}$ A significant reduction in size after antitubercular treatment has been reported as early as 2 months, usually with complete resolution of sellar mass at the end of the regimen. ${ }^{12}$

\section{Conclusion}

Pituitary tuberculoma, which is a rare lesion, should be included in the differential diagnosis of sellar lesions (pituitary adenoma, Rathke's cyst, craniopharyngioma, metastatic tumor, and inflammatory lesion). The presence of thickened bulky pituitary stalk on MRI may be an important clue to diagnose "pituitary tuberculosis." We also emphasize that the histopathological examination plays an important role in diagnosis and further management of this disease.

\section{Conflict of Interest}

None declared.

\section{References}

1 Behari S, Shinghal U, Jain M, et al. Clinicoradiological presentation, management options and a review of sellar and suprasellar tuberculomas. J Clin Neurosci 2009;16(12):1560-1566

2 Bernaerts A, Vanhoenacker FM, Parizel PM, et al. Tuberculosis of the central nervous system: overview of neuroradiological findings. Eur Radiol 2003;13(8):1876-1890

3 Desai K, Nadkarni T, Bhatjiwale M, Goel A. Intraventricular tuberculoma. Neurol Med Chir (Tokyo) 2002;42(11):501-503

4 Furtado SV, Venkatesh PK, Ghosal N, Hegde AS. Isolated sellar tuberculoma presenting with panhypopituitarism: clinical, diagnostic considerations and literature review. Neurol Sci 2011;32(2):301-304

5 Ghosh S, Chandy MJ. Intrasellar tuberculoma. Clin Neurol Neurosurg 1992;94(3):251-252

6 Sharma MC, Arora R, Mahapatra AK, Sarat-Chandra P, Gaikwad SB, Sarkar C. Intrasellar tuberculoma-an enigmatic pituitary infection: a series of 18 cases. Clin Neurol Neurosurg 2000;102(2):72-77

7 Sinha S, Singh AK, Tatke M, Singh D. Hypophyseal tuberculoma: direct radiosurgery is contraindicated for a lesion with a thickened pituitary stalk: case report. Neurosurgery 2000;46(3):735-738, discussion 738-739

8 Sugimori H, Saku Y, Ibayashi S, Ogasawara T, Fujishima M, Iida M. Solitary pontine tuberculoma. Intern Med 2002;41(9):738-742

9 Suslu HT, Bozbuga M, Bayindir C. Cerebral tuberculoma mimicking high grade glial tumor. Turk Neurosurg 2011;21(3):427-429

10 Yilmazlar S, Bekar A, Taskapilioglu O, Tolunay S. Isolated intrasellar tuberculoma mimicking pituitary adenoma. J Clin Neurosci 2007;14(5):477-481

11 Páramo C, de la Fuente J, Nodar A, Miramontes S, Quintela JL, García-Mayor RV. Intrasellar tuberculoma-a difficult diagnosis. Infection 2002;30(1):35-37

12 Gupta RK, Pandey R, Khan EM, Mittal P, Gujral RB, Chhabra DK. Intracranial tuberculomas: MRI signal intensity correlation with histopathology and localised proton spectroscopy. Magn Reson Imaging 1993;11(3):443-449 